\title{
From Literacy To Information Literacy: Reading For Understanding In The Real World
}

\author{
John Royce \\ Library Director \\ Robert College of Istanbul \\ TURKEY
}

\begin{abstract}
Good readers evaluate as they go along, open to triggers and alarms which warn that something is not quite right, or that something has not been understood. Evaluation is a vital component of information literacy, a keystone for reading with understanding. It is also a complex, complicated process. Failure to evaluate well may prove expensive. The nature and amount of information on the internet make evaluation skills ever more necessary. Looking at research studies in reading and in evaluation, real-life problems are suggested for teaching, modelling and discussion, to bring greater awareness to good, and to less good, readers.
\end{abstract}

\section{Introduction: Reading matters}

Karen Coyle relates how, in the early days of the World Wide Web, she proudly demonstrated the Internet to a visitor to the library. She thought she was picking out some really exciting hits, but her visitor was less than ecstatic, saying, "But it's just a bunch of reading" (Coyle, p.14)

This is a sad thought. Reading is a survival skill. Reading, and of course writing, enables learning. Reading and writing allow people far apart, in space and in time, to talk to each other. In recent times, other forms of communication have become more prominent, more available, often more entertaining. And yet the cinema has not killed reading, nor television, nor video. The computer, dvd and videodisk, mp3 and cell phones, they are not going to kill reading. We are probably reading more than ever. Arguably the first Internet sales success, the one which made online purchase safe and acceptable, was the online bookshop Amazon.com. We read. We read books, we read magazines, we read screens, we read printouts, we read recipe cards, we read.

The other side of reading is writing. Alphabets and writing developed in part because pictures and sounds were not always good at transmitting meaning. They may be better now, and they may be more permanent and transmittable, but this was not always so. A picture might be worth a thousand words, and the Internet has developed much since Coyle's hapless library customer, but it is still easier to find information in words on the Internet than it is to find information in sound or pictures. A bunch of reading it may be, but it's a bunch we cannot do without.

Spink (1989) suggests that the book as we know it may well disappear, but that the book as we know it is relatively recent. It replaced earlier writing technologies and will in turn be replaced. The medium changes but the words remain. 
"[Words] have appeared on clay tablets, on papyrus rolls, and in handwritten and printed books. It would seem that most of them are now appearing on VDUs, in thousands, millions, of words, figures, and images. Ther have to be read. that is, decoded and understood and acted upon" "Spink, p. 109).

These are vital points. Reading is not a one-way process, from writer to reader. Reading involves more than the mere decoding of symbols. Reading involves meaning, it involves understanding. It involves thought, and action, and reaction. A skilled reader will read what is stated but also read what is not stated; a skilled reader will relate what is read to his own knowledge and experience, and so be led to decision, or perhaps to indecision as when held beliefs are challenged. Reading is response (Spink, p. 6).

In today's world, we all need to read. Some people read better than others, some are shamed - sometimes ashamed - because they do not read very well. Many poor readers learn how to disguise the fact, and read the signs when they cannot read the words. But we all need to read, and those who read well survive better than those who do not.

Those who read, succeed. The others flounder, and may fail. Many studies show very clearly the consequences of limited reading competence, for instance that children with poor reading skills tend to have lower self-esteem, and are more likely to have discipline problems at school; that nearly two-thirds of the U.S. prison population is illiterate, and so are threequarters of unemployed adults (Fuchs et al, 2001).

\section{Information and information literacy}

Gawith (2001, Section: discrimination, para 3) asserts that one of the most important reasons for reading is empowerment. She suggests that "the most important attribute of the information literate citizen today (is) the ability to discriminate, to detect nonsense, bias, to challenge fact not grounded in evidenee; to distinguish between informed opinions and ignorant ranting." This is critical reading.

Neate (1992) suggests that we spend a lot of time teaching children how to read, especially narrative, but that we do not spend enough time teaching them different ways of reading, we do not teach them how to read to learn, and we do not spend enough time teaching information handling and learning skills. It is what you do with the reading that counts. Leppard (2003, Section: The new organisation of information, para. 1) declares, "While students need training in effective and efficient searches, there is now the particular challenge of teaching them how to judge the credibility of sources and the relative value of different types of information they have gathered."

The NEMP Studies in various teaching subjects confirm that children, in New Zealand at least, are good at finding information, but less good at deciding beforehand exactly what information they are looking for, or where to find it and how they will recognise it once found, or afterwards deciding what to do with the information they have found and how to use it (Gawith, 1998, paras 9-10).

If children ever had problems, and pre-Internet they might well have faced problems finding information in poorly-stocked and poorly-staffed school and public libraries, they certainly have no problem finding information today - as long as they have access to the Internet. But information alone is not enough. Information without purpose, without questions to be answered, is unnecessary, irrelevant, forgettable. Once obtained, information 
still needs to be handled, with discrimination, and some that is found may have to be rejected and some may be worth using.

\section{Prior knowledge and signals}

Neate (p. 130) pursues this line. If there is no purpose, it is difficult to know what is important in the text, in which case everything becomes equally important. She suggests that purpose depends on several factors, including reason for reading, motivation for reading, relation to what is already known and what must be found out, what one does with the reading, and similar considerations. Awakening prior knowledge and asking oneself questions before and during reading heightens alertness. Indeed, as McTighe and Reeves (2001, Critical thinking, para. 4) put it: "It is impossible to think critically about something of which one knows nothing."

Children, of course, are disadvantaged here, for their prior knowledge and awareness of relationships is necessarily limited.

Smith (1999) describes five strategies used by good readers: they predict what they are going to read, and revise their predictions as they go along; they picture what they are reading; they relate what they are reading to what they already know; they monitor their reading as they go along, and they resolve difficulties and discrepancies as they read or reread. Kibby (n.d.) and Wray and Lewis (1995) break their models down even further, but they are in firm agreement, good readers are active readers. Jacobs, state,

McTighe and Reeves (2001, Metacognitive reading strategies, para. 1), citing Paris \&

More effective readers employ metacognitive strategies before, during, and after their reading in order to facilitate comprehension ... Poor readers, on the other hand, tend to emphasise decoding ('word harking') rather than reading for meaning. They rarely utilise comprehension-monitoring or 'fix up' strategies.

Fitzgerald (1999, para. 2) emphasises the point. Reading for purpose involves more than just decoding words. It is part and parcel of a larger task. Quoting herself from an earlier paper, she declares,

Evaluation is an immensely difficult and complicated process. Research shows that evaluating information is a complex task usually performed within the context of an even more complex task, such as decision making or arguing. Also, the literature teems with examples of people failing to evaluate information well.

Instances abound. One of the most successful scams in recent years appears to have been the oilfield inheritance swindle. Why anyone who would sigh and delete yet another Nigerian 419 email would happily accept good news via phone call or headed notepaper, and then send off a cheque as advance fees just because there was a Thurso, Scotland address, is not yet clear. But it appears that many did (Seenan, 2003).

Evaluation, discrimination, critical reading, they are important. It is a commonplace to observe that the Internet has enabled anyone and everyone to publish anything, and there are 
no safeguards to ensure that what is published has authority. Traditional and especially academic publishing has safeguards such as editorial process, peer review, publisher's and author's reputation, the laws of libel and similar factors which combine to ensure that what is published has passed through a rigorous process which gives it some degree of aceeptance. accuracy and reliability. It does not guarantee accuracy or reliability, but in most cases the informed reader will be aware of factors which suggest political or religious bias, or a brand of sensational journalism, and so on.

There are no such safeguards on the Internet, where misinformation, disinformation, and propaganda are widespread, sometimes without and sometimes with devious or malicious intent. It is very much a case of reader beware (Kirk. 2002. Evaluating...). Unfortunately, many readers do not.

The activation of prior knowledge and the prediction of what the text is likely to say, or be about, are key factors in the interactive process. They aid understanding. and they enable interaction and response. They enable the active reader to become aware when something does not sound right, when there may be discrepancies between what is known and what one is reading.

Prior knowledge might not always be enough, but without prior knowledge there may never be awareness that something is wrong. Take, for instance, a search for Dr. Martin Luther King jr's "I have a dream" speech. Google will find more than 200 sites which use the phrase "colored American" throughout. Some of them have URLs which sound very credible, SeattleTimes.com, for instance, Colorado.edu, Historian.org, Usinfo.org, and similarly, should alarm bells ring?

But King did not use the term "colored American", and this version leaves out some parts of the speech and rearranges others. It shows King as inciting violence. The exhortation "In the process of gaining our rightful place we must not be guilty of wrongful deeds. Let us not seek to satisfy our thirst for freedom by drinking from the cup of bitterness and hatred" is omitted (Smith, 1997 (?); Royce, 1999).

This is rewriting history, misrepresenting it. If alarm bells should ring, then Google will find more than 12000 sites which use the term "Negro" and which do include those lines. Some of these sites have recordings of the speech or of parts of it. But why should those alarm bells ring without prior knowledge and careful reading?

Brunton (1999, para. 1) asserts, "None of us can independently verify everything we read or hear, so we must take on trust nearly all the information we receive." Fitzgerald, however, cites studies that show variously that some people think critically about what they read all of the time, that some evaluate some of the time, and that some appear to believe anything and everything they read without thinking twice. A great deal of evidence suggests that most people evaluate only when signalled that something is not quite right.

Signals are vital for the thinking reader. Signals may sound when one is skimming for information, as in "this is interesting, it looks worth a closer read". They also sound when discrepancies are seen, when the reader realises that something is not understood, or has been misunderstood, that something has been missed, or that the author is saying something which contradicts something said earlier, or contradicts something the reader knows or believes, or perhaps when the text just does not make sense. We are seeking triggers, listening for alarm 
bells. The arousal of prior knowledge and thinking while reading make those alarm bells more likely to sound as and when necessary.

Sometimes the trigger can be relatively trivial. A paper by Greer et al (2002) on web site evaluation, for instance, provides an excellent discussion of many issues. It is well researched, with plentiful citations. But in a discussion of uneven internet access around the world, a paragraph on Malawi stands out for its lack of attribution: amongst other claims, it is stated that communications are poor, especially in rural areas, and that there are no telephones in the country. The trigger for this writer was pure prior knowledge; he worked six years in Malawi in the eighties, and telephones there were. And still are, easily verified. For another reader, the signal must be the lack of attribution for this, a signal that may too easily be missed.

Sometimes the trigger will be something that does not sound very likely. A statement frequently quoted in articles on plagiarism is "Recent studies indicate that approximately 30 percent of all students may be plagiarising on every written assignment they complete," (Starr, 2002, para. 1). Thirty per cent? On EVERY written assignment'? How come these students are getting away with it, keep on getting away with it? How do the researchers know? Which researchers? None of the articles mention which recent studies; they only note that the statement comes from Plagiarism.org, the company behind Turnitin.com. The Plagiarism.org web site reports the findings of many surveys and investigations, all attributed, but this particular item is not attributed. Seeking verification, this researcher wrote to Plagiarism.org asking about these recent studies, but received no reply. Postings to several electronic mailing lists asked for further information, but nobody had anything to offer. The claim is no longer openly accessible, though it is still available at $<$ hutp://plagiarism.org/problem.huml> and it is still repeated in the press.

\section{Evaluation and evaluation checklists}

It is clear that some people do not evaluate as often, nor as deeply, as others. This could be why people who perhaps should know better fall foul of email fraud and other scams, are taken in by hoax sites and joke sites. Many people have visited Mankato, Minnesota, expecting a tropical paradise. The UK Sun newspaper was all too ready to believe it had secured photographs of Princess Diana in flagrante (Conned..., 1996). What can be done to help such people think more about what they read, to be more discriminating? And what about Hello! Magazine, or those who believe Elvis lives, or Roswell?

Many spoof pages and sites have been designed to amuse, or directly to make teaching points about the reliability of information on the Internet. Amongst the best known are the Mankato site, the Velero crop, and the Feline reactions to bearded men experiment. The best of these are very good, often very funny. But the good ones are few and may have become too well-known for teaching purposes. Some, such as Burger King's left handed burger press release (March 31, 1998), may deserve to be better known. Less good hoax sites tend to be more obvious, and are perhaps more difficult to use as teaching points. Against this, as demonstrated in this paper, there are many examples of genuine sites and pages that can be used for the teaching and practise of evaluation skills.

Googlebombs is a term coined to describe what happens when a hoax site is published, and gets so talked about, so well-linked, especially in the blogging community, that Google soon places it as Number One in its search results. Last year, a Google search for 
"Weapons of Mass Destruction" brought up a spoof error message, "These Weapons of Mass Destruction cannot be displayed". A similar prank made a search for "french military victories' bring up a page modelled on the Google misspelling warning: "Your search 'french military victories' did not match any documents; did you mean 'french military defeats"?"

These were fun because they were fairly obvious. Less obvious, perhaps, was the googlebomb that led a search for 'miserable failure' to link to a page on the official White House site, a biography of George W. Bush. Fun, yes, but worrying. It seems that Google can be easily manipulated. It is not funny when one does not know the manipulation is taking place. Close inspection will reveal that the page pointed to contains no use of the phrase 'miscrable failure', but what will trigger that close inspection'?

Indeed, Google, and other search engines, may manipulate themselves, without human intervention and without intention. Thus a Google search for 'fast' brings up AllTheWeb.com as hit number one; FAST technologies provide the search engine behind AllTheWeb.com. But a search for 'express OR rapid OR express OR fast OR speedy' also brings up AllTheWeb.com as hit number one, and so does a search for "diet OR starve OR fast OR abstain'. Johnson (2003) coined the term "Googleholes" to describe the dangers of blind faith in Google.

Some search engines sell space in their results listings; anyone selling anything can buy high placing in the results shown when inquirers search for specific terms. Given that many searchers do not look below the first few hits, this can be dangerous, especially for those who believe that the more relevant results are placed first. This does not apply to all search engines, some are impartial, but it does pay to know how one's favourite search engines place their results (Kirk, 2002).

Evaluation tools and guidelines have been developed, attempting to teach points to look for which might point to the authority and the reliability of what is read - or to the lack of it. As an example, the evaluation guidelines sites posted by Alexander and Tate (1999) and Schrock (2003) are among many often cited as exemplary. Such evaluation guidelines suggest criteria for consideration including:

- Authorship

- Publishing body

- Viewpoint or bias

- Prior knowledge (of the literature, context etc)

- Accuracy

- Verifiability of details

- Currency

These are very similar to the criteria suggested by Fisher $(2001$, p.93) in his book on critical thinking, for critical thinking is what evaluation is all about:

- Publisher's reputation

- Vested interest

- Independent corroboration

- Author's expertise/ training 
- Credible reasons for the claim

- The claim itself.

Indeed, the literature of logic and critical thinking provides examples of argumentation, reasoning and fallacious reasoning which can be used to extend the examples given in this paper.

Numbers might always demand close inspection. In the opening chapter of a book on how statistics can mislead, for instance, Best (2001) tells of a Ph.D. thesis he was moderating. The candidate had written a startling, attributed, opening sentence: "Every year since 1950, the number of American children gunned down has doubled, and homicide is the third leading cause of death for all children between the ages of five and fourteen."

Best calculated that if just one child had been gunned down in 1950, this would have doubled in 1951 to two children, doubled in 1952 to four children, and eight the next year. In 1995 there would, according to the claim, have been 3.5 trillion children gunned down in the U.S.A.

Best's first thought was that the student had copied the quotation incorrectly. He was wrong. In a search worth replicating, he traced the quotation back through two academic journals, the earlier of which was a paraphrase from the original text rather than a direct quotation. The original statement was made in a Children's Defense Fund yearbook, where is stated: "The number of American children killed each year by guns has doubled since 1950."

A few loose words and the paraphrase says something very different.

Best goes further. An alert reader might question the CDF statistic, and whether the fact that America's 1994 population was almost double that in 1950 should lessen the sensation of the doubling in the number of children gunned down. The alert reader will also notice the difference between "killed by guns" and "gunned down"; they are not the same.

Academically speaking, the citations in each of the three later papers using this statistic are flawed. The major citation guides all recommend that when citing secondary sources, the citation should note the original source as well as the source actually used. One reason academia requires citation and reference is to allow a reader to check directly any controversial statement, or to seek further information and advice. And here, as noted, the information is critically controversial.

Piper (2000, Conclusion, para. 5) opines "While Web literacy demands intelligent Internet use, Web literacy is really not qualitatively different than information literacy. All information has bias and has to succumb to rigorous evaluation." There is nothing wrong with bias; the information may be accurate and pertinent. When the reader is aware of bias, $\mathrm{s} / \mathrm{he}$ can then be aware of what may have been omitted from the discussion. Kirk repeatedly emphasises the need to check the information and the sources, to verify, and not to use anything that cannot be verified.

Evaluation checklists are useful, for they make for artificial triggers. However, few pages or sites gain a perfect score on all criteria. Schrock provides levels of checklist according to level of schooling, and this is to the good: evaluation criteria can be very sophisticated, and children's awareness of distinctions may be limited. Currency, for instance, may be an issue only if the information is fast-changing, or new information has recently 
emerged. A personal ( tilde) site should be acceptable if posted by a recognised authority in the subject: the tilde does not necessarily mean that it as the work of a layman or a student. Evaluation criteria serve as triggers, but the material may still be aceeptable.

Many evaluation checklists need updating in the light of experience: in particular, it is no longer safe to assume that the posting of information found on three different sites can be accepted as true, nor that material found on a .org site is any more independent and trustworthy than material found on a .com site. Even gov sites may be suspect. It is not simply a matter of bias, either; some sites set out deliberately to misinform. Compare, for instance, the <htpp: www galt.org > and the < hetp: www.wto.org > sites, which is the true World Trade Organization site? (Piper). One should never assume that the official site has been found, nor assume that the official site is unbiased. Kirk (2002, Information counterfeits..., Concluding paragraph) advises: "Always validate or confirm information on individuals, institutions or groups, and countries that you find on the Internet. If you don't know who wrote what you read or why they wrote it, you don't know if it's trustworthy."

\section{Developmental and psychological factors}

Fitzgerald's analysis (1999) includes studies which show that elementary school children can detect errors and inconsistencies if they are warned to watch out for them, and other studies which show that they are unlikely to find them if they are not warned. This may be because young children respect authority, it may be because they lack basic knowledge. It may be because they still find it easy to believe six impossible things before breakfast; Neate's Modelling process ( 1992) can be useful for identifying basic misunderstanding. Wray and Lewis (1995) suggest that it is natural for children to believe everything they read, trusting in the greater knowledge and experience of the adults who wrote the books. Both Fitzgerald and Wray and Lewis note Garner's study which suggests that better readers understand more of what they read, and that they are more likely to spot inconsistencies than poor readers.

Of course, it is not just young children who fail to spot inconsistencies. Evaluation failure is endemic. We tend not to question everything we read, especially when we know little about a subject and presume we are in the hands of someone who knows more than we do - and is being accurate, authoritative ete. When doing research, especially on the web, students are on their own, and much of the material they find is written at an inappropriate level, or may be biased, and so on. When doing research, when children do not understand, they are very tempted to copy (McGregor, 1998).

There is vital need for students to be trained and given opportunity to ask real questions, essential questions, to practise thoughtful reading and careful fact-finding. This would avoid meaningless project syndrome, which Gawith (1998, para. 20) describes, with caveat, as

Cognitive hypass learning - where facts come through the kerboard or pages and land on the screen or a bit of paper without heing processed through the mind. If all you ever do is paste up, manually or electronically, information that you find, if you never need to think about it. wrestle mentally with the concepts, compare, contrast, select, reject, collate and make inferences fiom it. bou might be computer literate but vou are certainly NOT INFORMATION LITERATE. 
We might practise with chain or scam email. Why, for instance, should an unknown international lottery be so careless as to mix up numbers, never mind all the spelling and grammar mistakes? The free email address should be a bit of a giveaway as well. But will our students know if they are not taught to watch out and what to watch for? (Royce, 2003).

Or, is there any truth to the "Cough to survive a heart attack" email which occasionally does the rounds? These and other urban legends can provide meat for discussion and thinking practice in real situations (Emery, 2003).

The problem of familiarity has already been touched upon. The scarcity of "good" hoax sites has been touched upon. It is up to individual teachers to compile a portfolio of sites which can be used, especially curriculum-related sites, as well as using sites mentioned in the literature. Recommended sources include blogs, scambuster pages, urban legends sites and similar. Examples abound. Pathfinders and webquests can be used to direct students to many sites worthy of discussion. Webquests may be particularly useful, for they really do emphasise the need for purpose: one person's irrelevant information may be gold for another researcher.

Figures are dangerous in the wrong hands, and so are search engines; these are golden areas for teaching evaluation skills. Dube (2003) highlights a newspaper report that a Google search for Iraq war yielded 3.2 million hits; Dube points out that a search for Iraq war on Google yielded more than 3 million hits only when no quotation marks were used. A search for "Iraq war" using quotation marks found about 635,000 hits, because Google now searched only for the exact phrase. Dube also notes that the number of hits is approximate, and should be reported as such; there is difference between "the search yielded 3.2 million hits" and "the search yielded about 3.2 million hits".

Citing search engine results can be treacherous indeed. One has to know how the search engine works, whether it ANDs search terms or ORs them, whether it uses family filters, and if so are they ON or OFF when you do your search. The way any particular search engine works may change over time. Alta Vista, for instance, once used a default $O R$ if no boolean term was used; now its default is AND. Earlier versions of Google did not recognise boolean terms at all, and it also ignored quotation marks and phrase scarches.

It is worth suggesting that any statement using numbers, especially very round or very exact numbers, should be read carefully. Brunton (1999, paras 1-2) emphasises the point:

None of us can independently verify everything we read or hear, so we must take on trust nearly all the information we receive. This makes us valnerable to factoids ... Factoids are statements that are either misleading, or about matters that are essentially unknowable. But through frequent repetition these pseudo-facts become accepted as true, distorting our view' of the world and its problems.

Many in education and training will have seen something along the lines of: We remember $\quad 10 \%$ of what we read

$20 \%$ of what we see

$30 \%$ of what we hear

$50 \%$ of what we hear and see

$70 \%$ of what we do. 
It is simple, and though the numbers are nicely round, it has a ring of common-sense. It may be so familiar that it is accepted as common knowledge. Closer reading might make for a trigger, and this is just as well, for these figures are meaningless and there is no research basis for them, they appear to have been plucked from the air (Work Learning Research. n.d.).

In similar vein are the simple percentages used in the Global Village scenario popular in chain email a few years ago:

If we could shrink the earth's population to a village of precisely 100 people, with all the existing human ratios remaining the same, it would look something like this:

57 Asians, 21 Europeans; 14 from the Western Hemisphere, both north and south, 8 Africans

52 would be female, 48 would be male

I would be near death; 1 would be near birth

1 (yes, only 1 ) would have a college education

1 would own a computer (cited in Balu, 2001).

Certainly there is nothing round about some of the figures, but unfortunately they have been plucked out of the air, they are not based on surveys or censuses or any other means of data collection and analysis (Balu, Engelken \& Grosso, 2001).

Psychological and personality studies pose further considerations. Fitzgerald eites studies which show variously that when new information agrees with existing knowledge, confidence in one's knowledge is increased, that when new knowledge conflicts with existing knowledge, it may simply be ignored. Some psychologists eall it "belief perseverance", a refusal to give up existing beliefs even when new information contradicts it, and perhaps even discredits it. Handy (1993, p. 78) calls it "selective perception", seeing only what we want to see. Two and more people can look at the same scene, but each may note different things, sometimes conflicting things.

We look for data to support our initial assumptions, and neglect or do not notice contradictory evidence ... we focus on what we want to see and ignore, do not see, things or behaviour that do not fit into our categories.

Is information biased when it agrees with or confirms our own point-of-view? It seems natural for us not to question what we read when it agrees with what we think we already know or believe. Piper advises:

The best protection one can have against misinformation is to adopt a critical stance toward all information on the Web. Parsuce the source of the information ... A dot-com or dot-org typically provides biased information. The bias ma! be slight. and it may be one pou agree with. hut it's usually. there. (Section: Hoax countermeasures, parall).

There is too a tendency for people deliberately to seck out information that confirms their beliefs, while ignoring information that contradicts it. Aside from which, when faced with a word or time limit, a student researcher is very likely to choose material which supports the hypothesis, and to pay no more than passing acknowledgement, at the most, to that which argues against.

History is subjective, and history can be manipulated. The versions of the "I have a dream" speech have already been mentioned. The Internet makes it all too easy to rewrite 
someone's words, too easy to rewrite history. Niman (2003) notes discussions in blogs and other media when President Bush's WhiteHouse.gov site began to block search engine access to certain pages in 2003, along with a suspicion that certain pages had been rewritten in the light of hindsight. He mentions also a contention that an extract from a book part-written by the first President Bush which had appeared in Time magazine under the title "Why we didn't remove Saddam" had been removed from the Time online archives. How to prove this allegation? It is not enough to confirm that this article does not exist in the archives; one must also go back to the printed magazine or to a periodical database to prove that the article existed in the first place. That both these factors prove true does not necessarily make for malicious intent. That both these factors prove true does not prove the truth of the other allegations either, but may provide extra weight, may make for motivation to explore them further.

\section{Metacognitive approaches}

Good readers are more discriminating than poor readers. Many of the studies cited by Wray and Lewis, by Fitzgerald, and by McTighe and Reeves affirm that reading skills and thinking skills can be and should be taught, modelled, demonstrate, practised. These strategies are effective. The studies show that metacognitive approaches to reading and in particular to evaluation do raise awareness and abilities.

Wray and Lewis suggest that teachers should "deliberately develop this questioning attitude ... deliberately to confront children with examples of out of date, biased or contradictory written material and to encourage them to discuss these features explicitly." McTighe and Reeves (2001a), Fitzgerald, and others add caveats: a good programme inculcates the skills over several years, they cannot all be taught once only, and they cannot be taught separately but need to be taught in the context of a subject area.

Gawith (1999, Section: Balance, para. 7) speaks forcibly on the need for the skills to be taught:

Each and every teacher should teach, model and demand evidence of students' ahility to scan and skim text, glean meaning from FAST reading through multiple information sources ... and EVALUATE as in sorting fact from opinion, determining authority in terms of information source, reliability and accuracy, comparing information, stripping out the key ideas, interrogating information sources.

Fitzgerald recommends a number of teaching strategies:

- Teach evaluation strategies one or several at a time over a span of years;

- It is not possible to evaluate all information ... (so it is important to) respond to signals and doubts that occur as they read;

- When a skill is introduced ... reduce cognitive load by breaking the skill down into smaller parts;

- In a daily 15-minute exercise, children should find problems such as inconsistency or exaggeration in a short piece of curriculum-relevant text;

- Ensure that cause is clear;

- Practice formal argumentation 
- Perform research regularly and intensely. Research should stem from either an authentic problem affecting the student or from personal interest because only motivated students exercise their optimal capabilities.

- Research projects should culminate in the production of different types of media. (Section: Teaching Strategies).

It is not just reading and critical reading we are talking about here, it is writing too. Just as we want our students to think eritically about all they read, they should think critically about all they write as well, they do need to evaluate their own work.

\section{Conclusion}

In the concluding remarks to her paper on evaluation. Fitzgerald asks:

Why do people continue to fall victim to these deceptions despite mumerous public varnings." Why do rabloid publications, notorious for printing inacerirate. ansubstantiated. and sensational information. contimue to sell issues:" Why do e-mail hocares, some of them almost as old as the lnternet. contime to circulate'? These incidents are fairly mild in import. Howe'er, the'y raise the question of whether an entire society could be fooled on matters of importance. Successfitl. although small, deceptions reflect the possibility that wholesale and ragic deceptions can oceur. (lmplications for Furnere research and Conclusion)

Again, it is not just scams and hoaxes. Careless thinking, dangerous propaganda, aggressive salesmanship abound. Fitzgerald may have been too cautious here, or perhaps not political enough, but then, it is only when they get found out that they get found out. It behoves us to be alert, and to teach our students how to stay alert. The lessons are clear and the examples are legion and everyday. They are there to be sought out, collected, and used. Critical thinking is empowerment.

\section{References}

Alexander, J., \& Tate, M. A. (1999). Evaluating Weh Resenteces. Retrieved February 3. 2004, from http: www2.widener.edu Wolfgram-Memorial-L ibrary webevaluation webeval.htm

Balu, R. (2001, March). Pleave den't forward this comail!' Retrieved February 3, 2004, from htp: www lasteompany.com/articles 2001 / 05 email.html

Balu, R., Ingelken, ( ., \& (irosso, J. (200) 1, May). Go aheded, fonwd this email!' Retrieved February 3. 2004. from hth: www fastcompany.com articles 200105 email 2 html

Best, J. (2001). Dammed lices and statistics: Introduction. Retrieved February 3. 2004. from htp: : www. Mepress edu books pages $9358935 \%$ intro.html

Brunton, R. (1999, May 8). Nuggets of misinformation. (owric' Mail. Retrieved January 2. 2004. from http. www ipalorg.au Media rbem()8(0599.html

Emery, D). (2003, September 2). (an coughing save your life during a heart attack") Ur.ben Le'gends and folklore. Retrieved February 3, 2004, from http : urbanlegends.aboul.com libary blepr.htm

Conned by cunning fraudsters. (1996, October 9). ( $N N$ Interative. Retrieved February 3, 2004, from Ittp: Www.con.com W(ORL.D) 961009 diama.hoax

coyle, K. (1997). Conle's information highway handhosk: a prectical file on the new information order. (hicago: American Library Association.

Dube, J. (2003, May 2). Misquoting (ioogle. Ponveronline. Retrieved February 3, 2004, from http. www.poynter.org dg. Its id.32 aid.320)72.column.htm

Fisher, A. (2001). (itical thinking: an introduction. (ambridge, England: Cambridge University Press. 
Fitzgerald. M. A. (1999). Fvaluating information: An information literacy challenge. School Library Media Resecarch. 2. Retrieved January 2, 2004, from hup://www.ala.org/Content/NavigationMenu/A ASL/Publications_and_Journals/School_Library_Medi i Rescarch/Contents / Volume 2 (1999)/vol2 fitzgerald.htm

Fuchs, D., Fuchs, L. S. Thompson. A., Svenson. E., Yen. L., Al Otaiba, S., et al. (2001, January/ February. Peer-assisted learning strategies in reading. Remedial and Special Education 22 (1), 15-21. Retrieved January 1, 2004, from http://www. Idonline.org/ld indepth/reading/peer_assisted.html

Gawith, G. (1997). NEMPing through information literacy. The SchoolQuarter/licom NZ Information Literac') Archive : Information Literecy: Definitions and Discassion. Retrieved January 6, 2004, from http:/web,archive.org/web/20020613231328/www.theschoolguarterly.com/info_lit_archive/detin_discu ssion/97 gg ntil.htm

Gawith, G. (1998). Ban projects - begin teaching information literacy... The SchoolQuarterly:com NZ Information Literacy Archive : Information Literacy : Leaning and Thinking, 1998. Retrieved January 1. 2004, from

htup:/web.archive.org/web/20021029183614/www theschoolquarterly.com/info lit archive/learning_t hinking/99 gg bptil.htm

Gawith, (i. (1999). Lost the plot: Reading for what? Keynote address (to the) Christehurch Reading Association, Christchurch, New Zealand, Saturday 19 June 1999. TheSchoolQuarterll'cem NZ Information Literary Archive: Learning and Thinking. Retrieved January 6, 2004, from

http:/web.archive.org/web/20021029184139/www.theschoolquarterly.com/info_lit_archive/learning_t hinking/99 gg lipriw.htm

Gawith, G. (2001). Why read?: Beyond the clichés of reading and information literacy. Keynote paper delivered at the Whangarei Reading Association inaugural seminar Saturday 10 March 2001.

TheSchoolQuarter/l.com NZ Information Literacy Archive : Information Literacy : definitions and discussion. Retrieved January 1, 2004, from

htlp:/web.archive.org/web/20030104184835/www.theschoolquarterly.com/info_lit_archise/defin diseu ssion/()) gg why read.htm

Greer, T., Holinga, D., Kindel, C., Netznik, M., Brown, J., Hickey, K. et al. (2002). Why evaluate web information. An Edacators' Guide to Credibility and Web Evaluation. Retrieved February 2, 2004. from http://rs.ed.uiuc.edu/wp/credibility/page2.html

Handy, C. (1993). Understanding Organizations (4 $4^{\text {th }}$ ed.). London: Penguin.

Johnson. S. (2003, July 16). Digging for Googleholes - Google may be our new god, but it's not omnipotent. S/ate. Retrieved February 2, 2004, from http://slate.msn.com/id/2085668/

Kibby, M. W. (n.d.). Thinking aleud and reading comprehension. Retrieved January 1, 2004, from http:/www.readingenter.buffilo.edu/center/research/hink.html

Kirk, E. (2002. February 12). Information and its conmterfeits: Propaganda. misinformation and disinformation. Retrieved January 1, 2004, from http://www.library.jhu.edu/elp/uscit/evaluate/counterfeit.html

Kirk, E. (2002, June 5). Evallating Internet information. Retrieved January 1, 2004, from http:/www.library.jhu.edu/elp/useit/evaluate/index.html

Leppard, L. (2003). The role of the teacher librarian in essential learning. Commentary 17 (3). Retrieved November 30, 2003, from hulp:/www.asla.org.au/aceess/a_conmentary_170303.htm

Mcciregor, J. H. (1998, Junc). Do scribes learn? copying and information Use. School Library Media Quarler/! Online I (1). Retrieved February 3, 2004, from http://www.ala.org/ala/aasl/aas/pubsandjournals/s/murb/s/mrcontents/rolumel/998s/mejo/mogregor.htm

McTighe. J.. \& and Reeves, B., eds. (2001a). Critical thinking. Thinking and leaming: What have' we learned ahout good instruction?" : School lmprovement in Maryland. Retrieved February 2, 2004, from http://Www.mdk 12.org/instruction/stlcess_mspap/general/projectbetter/thinkingskills/ts-17-20.html

McTighe, J., \& and Reeves, B., eds. (2001b). Metacognitive reading strategies. Thinking and leaning: W'hat hate we leaned about good instruction?': School lmprovement in Marylesnd, Retrieved February 1. 2004, from http/www.mdk 12.org/instruction/success_mspap/gencral/projectbetter/hinkingskills ts5.3-5.5.html

Neate, B. (1992). Finding out about finding out: A practical guide to children's information books. Sevenoaks. England: llodder and Stoughton.

Niman, M. 1. (2003. December 19), e-washing history one digital anchive at a time. Retrieved January 9, 2004, from hutp:/mediastudy.com/articles/av $12-11-3 . h t m l$

Piper, P. S. (2000, September). Better read that again: Web hoaxes and misinformation. Searcher $8(8)$. Retrieved January 2. 2004, from http://www. infotoday.com/seareher/seponipiper.htm

Royce. J. (1999. Autumn). Where the truth lies. The Schoo/ Librarian, 47 (3), 124-126. 
Royce, J. (2003, January 17). Is it a sc'am?' Retrieved February 2, 2004, from hllp / / m robcol.k 12.1r/ royce/sciml html

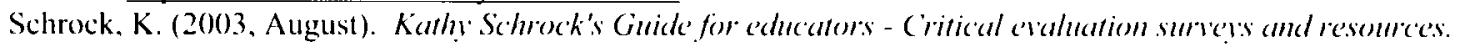
Available from hutp//school.discovery.com/schrockguide/eval.html

Seenan, (i. (2003. December 17). Pharmacy of false fortunes: Address of shop in Thurso given to victims of Nigerian scam. The Guardian. Retrieved January 16,2004, from http//www.guardian.co.uk/online/spam/story/0,13427,11085.30,00.html

Smith, A. (1997?). Limitations of Computers. Information Literecy. Retrieved 9 February, 2004, from littp:/2web.archive.org/web/19970108191625/http://inst.alugie.edu/asmith/limits.html

Smith, B. (1999). Uinderstemding the reading process. Retrieved January 1, 2004, from http:/academic.cuesta.edu/acasupp/as/302.htm

Spink, J. (1989). (hildren as recuders : a studh: London: Bingley/Library Association.

Starr, L. (2002. February 18). Put an End to Plagiarism in Your Classroom. Edecation W'orld. Retrieved February 3, 2004, from htep: www.education-world.coma curr curr 390.shtml

Work-Learning Research. (n.d.) Bogus Reseestch Uncovered. Retrieved February 3, 2004, from http/www.work-learning.com/chigraph.htm

Wray, D.. \& Lewis, M. (1995). Extending interactions with non-fiction texts: An exit into tunderstanding. Reculing 29 (1). Retrieved December 29, 2003, from htlp: www. Warwick.ac.uk/staff/D.J.Wray/excl/exit.htm]

\section{Author note}

John Royce has worked in Zambia, England, Malawi, Germany, and Turkey. Areas of research interest include literacy and information literacy, Internet search, plagiarism issues, and web page evaluation. Currently IASL Regional Director (North Africa and Middle East), he has twice chaired the ECIS Libraries Committee. He can be contacted at jroyce@robcol.k12.tr. 